\title{
Biology or Behavior: Which Is the Strongest Contributor to Weight Gain?
}

\author{
Nuala M. Byrne • Andrew P. Hills
}

Published online: 9 January 2013

(C) Springer Science+Business Media New York 2013

\begin{abstract}
Combating unhealthy weight gain is a major public health and clinical management issue. The extent of research into the etiology and pathophysiology of obesity has produced a wealth of evidence regarding the contributing factors. While aspects of the environment are 'obesogenic', weight gain is not inevitable for every individual. What then explains potentially unhealthy weight gain in individuals living within an environment where others remain lean? In this paper we explore the biological compensation that acts in response to a reduced energy intake by reducing energy needs, in order to defend against weight loss. We then examine the evidence that there is only a weak biological compensation to surplus energy supply, and that this allows behavior to drive weight gain. The extent to which biology impacts behavior is also considered.
\end{abstract}

Keywords Weight gain · Obesity · Determinants ·

Metabolism · Behavior · Biology

\section{Introduction}

It is a common phenomenon in many parts of the world for body weight to be gained over the adult years. In the past half century the prevalence of excessive unhealthy weight gain has markedly increased in many parts of the globe [1],

N. M. Byrne $(\bowtie)$

School of Exercise and Nutrition Sciences and Institute of Health and Biomedical Innovation, Queensland University of Technology, 60 Musk Avenue, Kelvin Grove,

Q4059, Brisbane, Australia

e-mail: n.byrne@qut.edu.au

\section{A. P. Hills}

Mater Mother's Hospital,

Mater Medical Research Institute and Griffith Health Institute,

Griffith University, Brisbane, QLD, Australia

e-mail: ahills@mmri.mater.org.au and has frequently been attributed to a lack of daily physical activity, and to the abundance of inexpensive, palatable and energy-dense foods [2]. There is no question that the environment plays a critical role in determining whether or not an individual is in a situation where they have the possibility of being in energy surplus, or positive energy balance [3-5]. We are able to view first-hand, or for most of us via our television screens, the consequences that befall communities such as those in Sub-Saharan Africa which experience continued famine. Without adequate energy intake, body weight cannot be maintained, let alone gained. Therefore, we can acknowledge the credence in the First Law of Thermodynamics, and note that for energy to be stored in the body tissues and for body weight to be gained; we must have an energy surplus to be stored. So moving beyond this basic tenet, what factors most strongly contribute to weight gain in individuals in the environmental circumstance where there is the opportunity to be in positive energy balance?

\section{Causes of Chronic Positive Energy Balance - a Complex Roadmap}

In addition to specific monogenic disorders $[6,7]$ that can lead to excessive weight gain from the first few months of life, a range of candidate genes have been identified which may mediate metabolic processes responsible for body weight regulation, and possibly may even explain propensity for weight gain [8]. Furthermore, there are a range biological factors which may, or may not be mediated by genetic predisposition, which impact on energy balance status in adults. These include, but are not restricted to: resting energy expenditure (REE), movement economy, body composition, meal-induced thermogenesis, appetite control and satiety, adipocyte metabolism, nutrient partitioning, gastrointestinal signaling, epigenetic factors, infection, emotional state and stress, and sleep quality [5, 9-16]. 
Additionally, there is evidence for behavioral factors that predispose an individual to a positive energy balance, and may be broadly categorized as energy intake (food and beverage consumption), level of physical activity and body movement, sleep habits, smoking, use of pharmaceutical and surgical treatments $[5,13,17-20]$.

Rather than being an "either/or" situation, the "drivers' for whether or not a person is in positive energy balance (largely environmental and behavioral) coexist with the 'determinants' of the amount of weight gained per unit positive energy balance (largely biological or metabolic). Further, the major drivers of positive energy balance, and the determinants of body weight gain, may not have the same potency of effect on energy storage and weight gain for all individuals. Despite considerable concerted research effort, what remains under debate is which factor(s) beyond the environment per se, has the strongest contribution to weight gain.

\section{Balancing the Energy Budget}

Weight stability requires that over time energy expenditure matches energy intake. When energy intake matches energy expenditure, the individual is in energy balance and consequently weight is stable (Energy Intake $=$ Energy Expenditure $\Rightarrow$ Energy Balance $\Rightarrow$ Stable Energy Stores $\Rightarrow$ Weight Stability). Importantly, weight stability per se can be achieved in chronically underweight, normal weight, and overweight conditions, albeit with considerable variability in the energy flux [21]. The energy balance equation correctly indicates that a change in either intake or expenditure will result in a concomitant change in energy stores and thus body weight. However, the equation belies the complexity of the numerous exchanges and transactions taking place within the individual who can experience large day-to-day fluctuations in energy intake and expenditure, and yet maintains longterm weight stability [22]. Consequently, due to the dynamic nature of the system, the model is more accurately explained as: Rate of change of energy stores $=$ Rate of energy intake - Rate of energy expenditure [23].

Although less detailed than the Foresight Obesity Systems Atlas [5], we have provided in Fig. 1 a simple model of the factors which determine body weight and composition. This model demonstrates the main biological (metabolic/physiological in grey) and behavioral or non-biological (in white) factors that explain daily energy expenditure and energy intake. In addition to activity energy expenditure (AEE), diet induced thermogenesis (DIT), and REE, there are other biological factors which can impact on daily energy expenditure in certain people and under particular circumstances.
For example the additional energy costs of pregnancy and body temperature regulation in the cold. Daily energy intake is largely determined by the composition and frequency of consumption, which is in turn influenced by food availability (environment) and affective factors such as food preference and imposed restraint. Importantly though, energy intake is also impacted by the biological signals of hunger and satiation. Both biology and behavior are, to varying degrees, influenced by genetic predisposition and the environment. It is accepted that interactions exist between the factors; however the relative contribution of each to body weight regulation remains unclear.

Both the energy balance equation and our model are true to the first law of thermodynamics [24], however neither can fully capture the mechanisms through which an acute, short-term change in energy balance does not result in the expected change in body weight. In part, this may be attributed to the fact that even when energy intake is precisely controlled, we do not have measurement tools sensitive enough to measure the change in energy expenditure or body energy stores that occur over a few days [25]. In terms of longer-term energy imbalance, there remains much uncertainty as to which factors account for why the weight change per unit energy excess or deficit is not uniform' [22, 26-30].

It is well accepted that a priority of all organisms is to maintain a stable internal environment in the face of variation in the external environment. The concept of 'homeostasis' as proposed by Claude Bernard was that: "All the vital mechanisms, varied as they are, have only one object, that of preserving constant the conditions of life". With regards to body weight regulation, we must consider what constitutes the "vital mechanisms", and how these are altered by a change in energy balance. Further, if we consider that the term homeostasis refers to the body's capacity to maintain balance in the presence of continual environmental variation, we may consider the prefix "homeo" to mean similar rather than same (i.e., homo). This infers there is a range of tolerable values within which the system can operate without undue challenge to health. For example body temperature of adults is not static at $37{ }^{\circ} \mathrm{C}$, but rather normally fluctuates about $0.5^{\circ} \mathrm{C}\left(0.9^{\circ} \mathrm{F}\right)$ throughout the day, and can range a few degrees before health is challenged. With regards to energy metabolism and body weight regulation, we need to consider if there is a threshold of change in energy intake (under-consumption and overconsumption) that needs to be reached before this change is registered and compensatory responses instigated. Further, if this does occur, what is the nature of the compensatory response(s) - biological or behavioral; and if both, is there a causal association? 
Fig. 1 Determinants of body weight and body composition.

$\mathrm{TEE}=$ total energy expenditure;

$\mathrm{REE}=$ resting energy

expenditure; DIT $=$ dietary

induced thermogenesis; $\mathrm{AEE}=$ activity energy expenditure;

ExEE $=$ exercise energy

expenditure; $\mathrm{NEAT}=$ non-

exercise activity thermogenesis;

Other $=$ factors such as non-

shivering thermogenesis

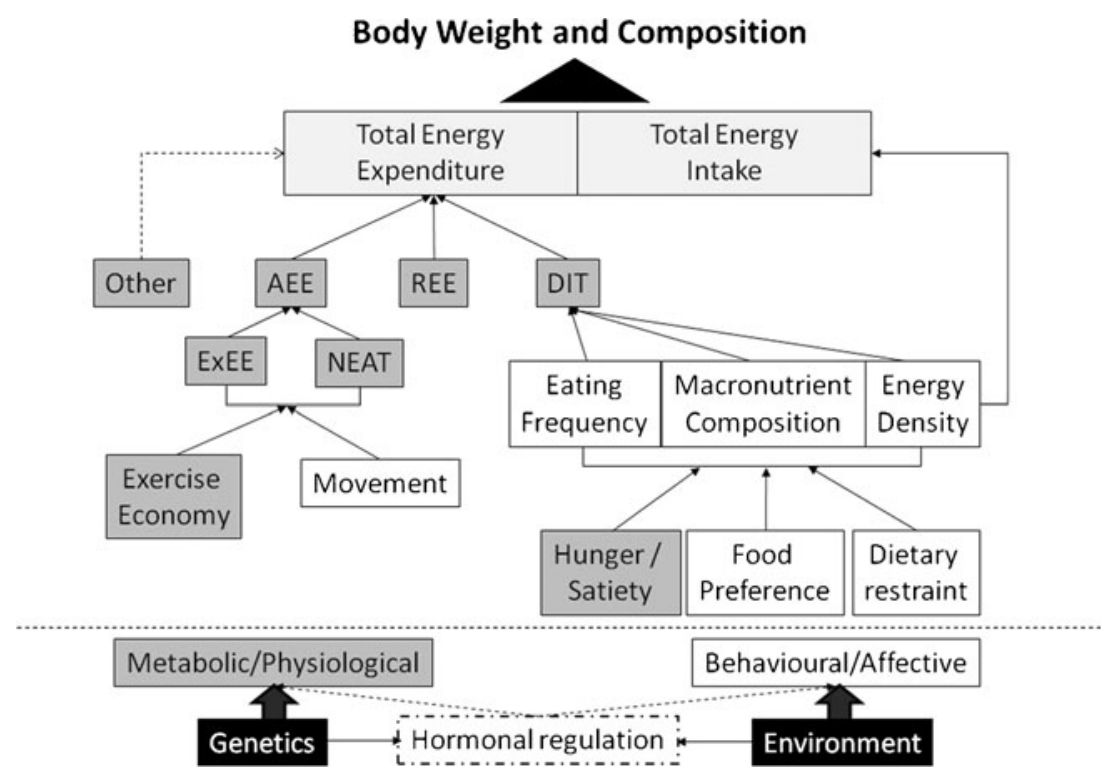

\section{Metabolism Acts to Limit Losses in Body Weight (Energy Stores)}

Heal et al. [12] note that given that the maintenance of a balance between energy intake and expenditure is essential for survival, these physiological processes are regulated by a complex network of peripheral and central signaling pathways. However, signals related to energy depletion may be stronger than those from excess energy stores [31]. Biological compensatory responses are elicited when energy restriction is imposed, essentially acting to reduce energy expenditure [32], which in turn reduces the energy deficit and can reduce the weight lost [33]. It is well accepted that resting energy expenditure (REE), which constitutes the largest proportion of total daily energy expenditure, decreases substantially during energy restriction even before significant weight loss has occurred [34-37]. Other energy restriction studies demonstrate rapid alterations in gene expression of enzymes regulating cellular metabolism, and that these changes occur in response to changes in energy intake per se rather than as a consequence of weight loss [38, 39].

It has been repeatedly shown that by the end of prolonged continuous (12-14 week) energy restriction, the energy deficit elicits as little as $60 \%$ of the expected change in body weight and fat mass $[9,26,27,40]$. We have recently reported that reductions in REE explained a large proportion of the less-than-expected weight loss in obese adults, and that this is already evident early in the energy restriction period (i.e., within the first 4 weeks) [30]. In this same cohort we found that the relationship between REE and body composition was strongly affected by energy restriction [41]. Over the 12 weeks of severe energy restriction and exercise training, $9.3 \pm 3.3,5.1 \pm 1.3$ and $4.2 \pm 1.4 \mathrm{~kg}$ of weight was lost in months 1,2 , and 3, respectively. Fat-free mass explained $75 \%$ of the between-individual variance in REE at baseline, with fat mass explaining a further $13 \%\left(\right.$ model $\left.\mathrm{R}^{2}=0.88\right)$. A comparable model was found at the completion of the intervention $\left(\mathrm{R}^{2}=0.89\right)$. However markedly more variance in REE could be explained by fat-free mass and fat mass after month-1 $\left(\mathrm{R}^{2}=0.96\right)$ and month- $2\left(\mathrm{R}^{2}=0.95\right)$ of energy restriction. These findings suggest that compared with energy balance, resting thermogenesis during energy restriction is more strongly associated with the energy needs of body tissues, and energy expenditure superfluous to servicing these tissues is reduced. Given the relative energy deficit from baseline requirements was severe (74$87 \%$ ), we would expect marked metabolic compensation in reducing energetic support to the non-vital mechanisms.

The effect of energy restriction to reduce REE, and increase the efficiency of weight loss, may be mediated in part by neuroendocrine pathways [42]. For example, energy restriction leads to reduced function of the hypothalamopituitary-thyroid and possibly also the -gonadotropic axes, indicated by reduced circulating concentrations of thyroidstimulating hormone, functional thyroid hormones (e.g., free triiodothyronine or $\mathrm{T} 3$ and free thyroxine or $\mathrm{T} 4$ ) [43-45], follicle-stimulating hormone, luteinizing hormone, and testosterone $[44,46]$, as well as reduced circulating insulin-like growth factor-1, plus increased function of the hypothalamo-pituitary-adrenal axis, indicated by elevated circulating adrenocorticotropic hormone and cortisol concentrations $[32,34]$. The homeostatic drive to eat (i.e., hunger) is a well established response to acute and chronic energy restriction. The orexigenic response to energy restriction and weight loss is the body's protective mechanism to prevent an indefinite weight loss. Fasting hunger 
significantly increases in association with a loss in body weight [47], and also increased acutely with energy restriction before appreciable weight loss [48]. Furthermore, hunger is a strong predictor of energy intake $[49,50]$, therefore a compensatory increase in the drive to eat in response to energy deficit and consequent weight loss will contribute to a resistance to continued weight loss, or even promote weight regain. Indeed, the weight loss-induced increase in hunger is a significant predictor of subsequent weight regain in humans [51] and in diet-induced obese rats [52, 53].

While automatic physiological compensation occurs during energy restriction, behavioral compensatory reductions in physical activity may also contribute to lowering daily energy expenditure, which may ultimately constrain weight loss. Activity energy expenditure (AEE) is a function both of the total amount of physical movement as well as the efficiency, or energy cost, per unit of that movement. Physical activity [20,54] and the energy cost of movement [55, 56] reduce during energy restriction. In humans, compensatory decreases in AEE in response to energy restriction and/ or exercise training $[17,55,57]$, can equate to $>175 \mathrm{kcal} /$ day, with evidence of greater reductions in AEE with more severe energy restriction [55]. In mice, differences in physical activity accounted for a significant amount of the variance in weight loss in a study where energy was restricted to $70 \%$ of baseline energy intake for 28 days [58]. The mice losing more weight had increased, and the mice losing less weight decreased physical activity levels.

Collectively the results presented above paint a picture of a biologically-driven and behaviorally-effected system working to counteract the negative energy balance imposed. Over the months that continuous energy restriction interventions are typically used, these reductions in resting and activity thermogenesis, increased hunger, and reduced movement likely contribute to significantly reduced weight loss efficiency. While the hypothalamus is recognized as the "master controller" driving the biological compensatory responses [59], the extent to which these signals are responsible for driving the behavioral compensatory responses is uncertain. Parker and Bloom [14] provide a compelling case that neuropeptides are involved in the regulation of appetite. However, they are duly cautious to note that while there is evidence that a given neuropeptide activates certain regions of the brain, or regulates the expression or release of other neuropeptides, there is not the evidence to show how the release of a peptide leads to the complex behavioral response of feeding.

Although no research using appropriately sensitive methods has quantified the magnitude of effect of biology and behavior, it is likely that the defense is orchestrated by biological signals. The key intracellular signaling protein AMP-activated protein kinase (AMPK) may serve an important role in regulating the skeletal muscle response to negative energy balance because it functions as a fuel sensor in many tissues, including skeletal muscle, and inhibits anabolic signaling pathways when cellular ATP levels are decreased and AMP levels increase in response to limited energy availability [60]. To date there have been limited in vivo human studies assessing intracellular regulation of skeletal muscle protein metabolism in response to negative energy balance [61], however it is likely this intracellular signaling protein may explain differences in weight loss efficiency .

These combined compensatory responses represent a multi-pronged defense of energy stores which, through its effectiveness, has enabled humans (and other organisms) to survive numerous famines over the millennia. The biological imperative of such metabolic compensation during negative energy balance, and particularly with severe energy restriction, was recognized in 1950 by Ancel Keys who noted: It might seem entirely reasonable that the energetic processes of the body diminish in intensity as the exogenous food supply is reduced. It is reasonable in the sense that a wise man will reduce his expenditure when his income is cut [36]. What remains unclear from the available evidence is whether there is a lower threshold of energy restriction (or macronutrient restriction, e.g., protein) to which the cavalry is rallied to defend. Finally, if the body uses inbuilt homeostatic mechanisms to defend against ongoing energy restriction and weight loss, to what degree are these same mechanisms driven to limit weight gains by countering a positive energy balance?

\section{To What Degree Does Genetic Predisposition Predict Weight Gain?}

Why do some individuals gain weight in an obesogenic environment, while others don't? As previously mentioned there are a number of monogenic disorders that are responsible for obesity [6, 7]. However, monogenic disorders are rare, and the potency of this effect should not be extrapolated to infer that weight gain in the vast majority of obese individuals is primarily caused by genetics. Loos [8] recently examined evidence of the genetic determinants of common obesity from genomewide association studies (GWAS), and their value in predicting weight gain. At least 52 genetic loci have been identified that are considered unequivocally to be associated with obesity-susceptibility. However despite highly significant associations and repeated replication, Loos noted that "the effects of the established loci on obesity-susceptibility are small and explain only a fraction of the total variance," and that "the ability of these 
loci to predict obesity is poor and not competitive with the predictive ability of traditional risk factors such as parental and childhood obesity."

The 32 loci which most strongly related to obesity combined explained only $1.45 \%$ of the phenotypic variation in BMI, equivalent to $24 \%$ of the heritability [8]. Importantly, having or not-having a genetic loci is only part of the picture; there is also the requirement of being in an environment that will support the full expression of the genotype. However, given the environments where the GWAS studies have been conducted are likely very supportive of energy surplus, there appears to be considerable phenotypic plasticity [62]. A better understanding of the physiological pathways that may be regulated by particular genetic loci is needed.

Genetic predisposition to weight gain has also been examined via studies of monozygotic twins. In their highly-controlled metabolic ward study, Bouchard et al. [9] reported considerable inter-individual differences in weight gain after overfeeding (1000 kcal/day, $6 \mathrm{~d} / \mathrm{wk}, 100$ d), with three and a half times more variance in weight gain between pairs than within twin-pairs. These results provided evidence that being genetically similar, related to a more similar response to surplus energy consumption. While a seminal finding, it is important to remember that the male participants were all lean, with no family history of obesity, so were not considered at risk for obesity. Despite their phenotype at baseline, over the 84 days of overfeeding and remaining sedentary, all participants gained weight, with the average weight gain of $8.1 \mathrm{~kg}$ (range: 4.3 to $13.3 \mathrm{~kg}$ ). Further, it was calculated that the weight gain attained in the experiment reached about $55 \%$ of the anticipated weight gain had that same level of overfeeding been continued [63]. From baseline to the end of the intervention, body weight increased on average $13.4 \%$, body fat increased from $11.3 \%$ to $17.8 \%$, and BMI increased from 19.7 to $22.4 \mathrm{~kg} / \mathrm{m}^{2}$.

Had the intervention continued at this, now reducing, relative overload, on average weight would have increased $\sim 24 \%$ from baseline, BMI would have been bordering overweight $\left(\sim 25 \mathrm{~kg} / \mathrm{m}^{2}\right)$ and body fat would likely have increased above $30 \%$. These data further support the opposition [24] to the idea that certain individuals have the capacity to completely 'burn off' surplus energy, i.e., luxuskonsumption. In this study, the dietinduced thermogenesis was not modified by overfeeding. Further, while the intra-pair resemblance in response was particularly strong for changes in body mass, body composition, subcutaneous fat distribution and abdominal visceral fat, two long-term intervention studies showed no genetic influence on variations in REE [64]. Importantly, the increase in REE of $\sim 10 \%$ was largely explained by the change in body composition $[65,66]$, and the absolute increase would account for only $\sim 15 \%$ of the surplus energy consumed.

We may strongly argue from this data that in an environment supporting energy surplus, with behaviors exploiting these surplus, normally lean individuals can gain significant weight without genetic or biological protection. This is in contrast to the previously outlined research demonstrating the pervasive biological protection against energy restriction acting to mediate weight loss, albeit that the extent to which may be explained by genetics. However like the energy restriction studies, it is unclear what might be a threshold of persistent overconsumption below which there is no resulting energy storing, but rather simply increased oxidation. Further, if a threshold exists, does it differ between people?

\section{Epigenetics - When is the dye Cast?}

Epidemiological studies have reported a U-shaped relationship between birth weight and adult adiposity, with a higher prevalence of adult obesity occurring in individuals with birth weights either at the low or high end of the birth weight distribution [67]. The 'developmental origins of adult health and disease' hypothesis was born from epidemiological research which found that early inadequate nutrition, either in utero or in infancy, was predictive of long-term weight gain and metabolic dysfunction [68, 69]. Research using sheep models have demonstrated that exposure to maternal overnutrition in the periconceptional period alone results in an increased body fat mass in the offspring, and that a short period of dietary restriction can reverse this effect [70]. Other research has shown that altering the protein intake in the diet of heifers during gestation has permanent sexand depot-specific effects on the expression of adipogenic and adipocytokine genes and offspring adiposity [71]. In addition to the in utero environment during gestation, periconceptional health status of both parents is recognized as impacting on fetal development and its longer term weight gain and chronic disease risk [72, 73]. Given the significant weight loss many obese women undertake in the quest for improved fertility, it is critical to understand the metabolic and developmental consequences of the often severe caloric restriction experienced by these women on oocyte and later fetal development [72].

\section{Influence of Biology and Behavior on Weight Gain - Central Characters or Supporting Cast?}

The evidence provided above supports the premise that the signals related to energy restriction may be stronger than 
Table 1 Determinants of weight gain: selection of studies from 2011-2012

\begin{tabular}{|c|c|}
\hline Study & Findings \\
\hline Bostrom et al. $[90 \bullet]$ & $\begin{array}{l}\text { In this mouse study the transcriptional co-activator PPAR- } \gamma \\
\text { co-activator-1 } \alpha \text { (PGC1- } \alpha \text { ) expression in muscle was } \\
\text { found to stimulate an increase in expression of FNDC5, a } \\
\text { membrane protein that is cleaved and secreted as a newly } \\
\text { identified hormone, irisin. Irisin acts on white adipose } \\
\text { cells in culture and in vivo to stimulate UCP1 expression } \\
\text { and a broad program of brown-fat-like development. } \\
\text { Mildly increased irisin levels in the blood cause an in- } \\
\text { crease in energy expenditure in mice with no changes in } \\
\text { movement or food intake. }\end{array}$ \\
\hline
\end{tabular}

Elks et al. [91•]

A longitudinal British birth cohort was genotyped for 11 genetic variants associated with adult BMI. The obesityrisk-allele score showed borderline significant association with birth weight and with higher weight and BMI at all time points between ages 2 and $53 \mathrm{y}$; the strongest associations with weight occurred at ages 11 and $20 \mathrm{y}$.

Faghihnia et al. [92•] Alterations in energy substrate partitioning or efficiency were assessed by indirect calorimetry in men with Atherogenic lipoprotein phenotype (ALP+) and unaffected controls (ALP-) during rest (30 $\mathrm{min})$ and exercise (10 min). Respiratory exchange ratios (RER) were significantly higher and lipid oxidation lower in $\mathrm{ALP}(+)$ vs. ALP(-) during rest and exercise. Gross and net efficiencies were significantly increased in ALP $(+)$. RER was correlated positively with plasma triglyceride during exercise and inversely with HDL-cholesterol and LDL peak particle diameter during rest and exercise.

Tomiyama et al. [93•] This study examined whether leptin reactivity accounts for individual differences in stress eating. Increasing leptin during an acute psychological laboratory stress test predicted lower intake of comfort food. Acute changes in leptin may be one of the factors modulating down the consumption of comfort food following stress.

Vijgen et al. [94•]

Delany et al. [95•] recruited in adult humans, by observing BAT activity in ten morbidly obese subjects before and after weight loss induced by bariatric surgery. The mean weight loss was $36.1 \pm 8.3 \mathrm{~kg}$ with a mean percentage of weight loss of $28.7 \pm 6.2 \%$. While before surgery only $2 / 10$ showed active BAT, this increased to 5/10 12-months postsurgery. After weight loss, BAT-positive subjects had significantly higher non-shivering thermogenesis (NST) compared with BAT-negative subjects.

This study compared each component of energy expenditure in lean and obese individuals. Total daily (TEE), Resting (REE) and Activity (AEE) energy expenditure were all elevated in obese individuals. After
This study examined if brown adipose tissue (BAT) can be
Commentary: relevance and significance

The idea of a magic pill/injection substitute for exercise training has its attractions, particularly to aid individuals with movement disability. Apart from mirroring the elevated energy expenditure, the possibility that irisin can also mediate improvements in glucose homeostasis, is promising. However, exercise benefits are multifaceted, and usually require a progressive overload to prevent a plateau and to maximise health outcomes. Whether irisin dosage would need also to be progressively overloaded, and if any of the other functional benefits of exercise can be gained with irisin, remains to be seen.

The combined influence of adult obesity susceptibility variants on increased rate of weight gain was confined to the first $11 \mathrm{y}$ of life rather than continuing into later adolescence and adulthood. However, differences in BMI continued to track throughout adult life, which may suggest persistence of their effects on energy homeostasis. Importantly though, the effect is arguably small, with the risk-allele score explaining only $1.6 \%$ of the variance in weight SD score.

These findings suggest that increased muscular efficiency at low exercise intensity and reduced lipid oxidation during rest and exercise may contribute to both dyslipidemia and increased adiposity in individuals with ALP. Metabolic inflexibility is impairment in the ability to switch between carbohydrate and fat oxidation when a metabolic stress is imposed (e.g., alteration in nutrient availability or exercise). However, fat oxidation, both at rest and during exercise, may be improved by exercise training. This study may provide further impetus to encourage exercise training, particularly for those who are $\operatorname{ALP}(+)$.

Stress is known to alter feeding responses in a bidirectional pattern, with both increases and decreases in intake observed. This study documented the heterogeneity of leptin responses to acute stress. Increases of circulating leptin concentrations during a psychological stress task predicted less consumption of high fat, high sugar foods. This suggests that leptin reactivity may be implicated in reducing stress-induced eating behavior. Whether the laboratory challenge reflects the responses to constant life stressors requires further investigation.

The results suggest that BAT was recruited in the regions in which it was previously reported in lean subjects. However, the BAT activity observed in this study was low in comparison with the levels observed in lean young men. Further, it was not clear what other biological characteristics differed between the BAT-positive and BAT-negative participants. How the change in NST reported in this study would affect daily energy expenditure under usual thermal exposures was not clear, however this research may open avenues for the pharmacological approach to increase thermogenesis using BAT. Further, given the extensive weight loss in this study, future studies may also consider the weight loss threshold needed to see these effects.

There was no indication of metabolic efficiency in even the severely obese, as adjusted REE was similar across all groups. The study demonstrated a lower volume of physical activity in the obese, and the total time spent in 
Table 1 (continued)

Study Findings Commentary: relevance and significance

appropriate adjustment, REE was similar in all groups. Analysis of AEE by body weight and obesity class indicated a lower AEE in obese individuals. Confirming lower physical activity, obese individuals spent less time engaged in moderate-to-vigorous physical activity and more time in sedentary behaviors.

St.Onge et al. [96•]

Normal weight adults who regularly slept $7-9$ h/night were recruited to participate in a crossover inpatient study. All participants were studied under short $(4 \mathrm{~h} /$ night $)$ and habitual $(9 \mathrm{~h} /$ night) sleep conditions. Participants consumed more $(\sim 300 \mathrm{kcal})$ energy during short sleep days. This effect was mostly due to increased consumption of fat. Resting metabolic rate and total energy expenditure did not differ significantly between sleep phases.

Britton et al. [97•]

Caprio $[100 \bullet]$
The study prospectively assessed whether moderate- and vigorous-intensity as well as total leisure-time physical activity (LTPA) were associated with the risk of becoming either overweight or obese using a prospective cohort design of 19,003 women enrolled in the Women's Health Study. During a median follow-up of 11.6 years, 7,865 women became overweight/obese. Both vigorousintensity and total LTPA showed a modest inverse relationship with the development of overweight/obesity. A greater percentage of total LTPA spent performing vigorous intensity activities was associated with a lower risk of overweight/obesity.

Caprio has reviewed three studies published in the New England Journal of Medicine $(2012 ; 367)$ providing evidence that consumption of sugar-sweetened beverages may influence the development of obesity in different age groups.

[1] Qi et al. (2012;367:1387-1396) examined the interaction between the intake of sugar-sweetened beverages and a genetic-predisposition score that was calculated on the basis of 32 body-mass index (BMI) loci associated with obesity in women and men from two large prospective cohorts and in an independent replication cohort. This study provided evidence that there is a significant interaction between intake of sugar-sweetened beverages and a genetic-predisposition score, obesity, and the risk of obesity. moderate-to-vigorous physical activity and average daily metabolic equivalent of task level were lower with increasing obesity. These findings demonstrate that high body weight in obese individuals leads to a high TEE and AEE, which masks the fact that they are less physically active, which can be influenced by duration or intensity of activity, than in lean individuals.

This data indicates that a reduction in sleep can increase energy and fat intakes, which may explain the associations observed between sleep and obesity. The increase in energy intake was not compensated by increased energy expenditure. Other research from the same group indicates that sleep quality is also compromised by reducing sleep duration, and this also relates to changes in food preferences and intake. Given this was an inpatient study, more research is needed to examine the impact of reduced sleep on free-living activity patterns.

In women who performed $\geq 50 \%$ of their total LTPA as vigorous-intensity activities, the hazard ratios $(95 \% \mathrm{CI})$ for the multivariable-adjusted model was $0.82(0.77-$ 0.88 ), and was attenuated, but remained significant after adjustment for baseline BMI, 0.92 (0.86-0.99). The Authors concluded that higher amounts of total LTPA should be encouraged to prevent obesity in individuals were such activities are not contraindicated. This adds to the growing body of evidence that well-designed programs of high-intensity interval training is tolerable for untrained and obese individuals, and provides additional benefits over low- and moderate-intensity training [98•, 99•].

The implications from these studies are:

(1) Participants with a greater genetic predisposition may be more susceptible to the adverse effects of sugarsweetened beverages on obesity. However this interaction is apparent only when a score is calculated from multiple genetic variants. As noted by Caprio, the mechanisms accounting for the observed interaction are not provided by the study. However, the findings suggest there may be merit in interventions aimed at reducing the intake of sugary drinks to reduce the risk of obesity, to be particularly targeted at individuals with a high geneticpredisposition score.

(2) The fact that a reasonable proportion of the cohort did not complete the study is recognised to be a limitation for the interpretation of the data. However, for the time they were enrolled, their responses matched that of the completers. Another important feature of the design was that the 18-month study duration ensured that the observed effect was not transient. The assumption that the mean changes in other factors that affect weight were also similar between the groups is not well justified. However, the results provide promise that weight gain from sweet beverage consumption may be offset by replacement with noncaloric beverages.

(3) The provision of noncaloric beverages was found to virtually eliminate reported consumption of sugarsweetened beverages and reduce total reported energy intake among overweight and obese adolescents after a 1year intervention. The Authors acknowledged that the 
Table 1 (continued)

\begin{tabular}{|c|c|c|}
\hline Study & Findings & Commentary: relevance and significance \\
\hline & & $\begin{array}{l}\text { intensity of the intervention, rather than provision of } \\
\text { noncaloric beverages per se, may have led to beneficial } \\
\text { changes in other behaviors, such as decreased television } \\
\text { viewing. }\end{array}$ \\
\hline & $\begin{array}{l}\text { [2] The study by de Ruyter et al. (2012;367:1397-1406) } \\
\text { employed a double-blind design in } 641 \text { primarily normal- } \\
\text { weight schoolchildren from } 4 \text { years } 10 \text { months to } 11 \text { years } \\
11 \text { months of age, where children were with } 1 \text { can per day } \\
\text { of a noncaloric, artificially sweetened, noncarbonated } \\
\text { beverage or a sugar-containing noncarbonated beverage. } \\
\text { Although } 26 \% \text { of the cohort did not complete the study, } \\
\text { the results provided evidence that masked replacement of } \\
\text { a sugar-containing beverage (104 kcal) with a sugar-free } \\
\text { beverage significantly reduced weight gain and fat accu- } \\
\text { mulation in normal-weight children. }\end{array}$ & $\begin{array}{l}\text { Taken together, these studies suggest that calories from } \\
\text { sugar-sweetened beverages may play an important role in } \\
\text { weight gain. However, whether promotion of artificially } \\
\text { sweetened beverages is the best alternative, or other } \\
\text { options such as water should be considered, particularly } \\
\text { in the children. }\end{array}$ \\
\hline & $\begin{array}{l}\text { [3] Ebbeling et al. (2012;367:1407-1416) randomly } \\
\text { assigned } 224 \text { overweight/obese adolescents who } \\
\text { regularly consumed sugar-sweetened beverages to ex- } \\
\text { perimental and control groups. The experimental group } \\
\text { received a 1-year intervention consisting of home deliv- } \\
\text { ery of noncaloric beverages. The difference in the pri- } \\
\text { mary outcome, the change in BMI at } 2 \text { years between the } \\
\text { experimental and control groups, was not significant. At } \\
1 \text { year, significant changes in BMI were observed, par- } \\
\text { ticularly among Hispanic participants, but were modest, } \\
\text { occurring mainly in a very small number of obese His- } \\
\text { panic adolescents, and they were not sustained at } 2 \text { years. }\end{array}$ & \\
\hline
\end{tabular}

those from excess energy stores [31]. While we are biologically predisposed to store energy, when the energy surplus is supplied at a high rate, as is often the case in experimental models (e.g., $1000 \mathrm{kcal} /$ day excess) [9, 74], there is some weak biological compensation which results in a somewhat less-than-expected weight gain. However, the weight gain efficiency in studies with a large and constant energy excess likely underestimates the conversion seen with the more modest overconsumption reflecting the 'creeping obesity' that is characteristic of population weight gain. Further, while studies examining weight gain via experimental manipulation are valuable $[9,64,74]$, they cannot inform us on the relative influence of biological mediators of metabolic rate versus behavior on the energy imbalance leading to usual (non-experimental) weight gain.

The "energy gap" calculation proposed by Hill et al. [75], used longitudinal epidemiological data to calculate the energy imbalance associated with the average weight change in a population at two time periods. Thus, the often quoted $100 \mathrm{kcal} /$ day "energy gap" value represents the estimated energy imbalance needed to maintain the mean weight change in a population over time. However, using the same approach and assumptions as Hill et al. [75], Butte and Ellis [76] found a deficit of 342-502 kcal/ day would be required to prevent further weight gain in $90 \%$ of overweight children. Similarly Wang et al. [77], using data of 12-17 year olds, calculated that the "energy gap" associated with the population weight gain in adolescents ranged from 678 to $1017 \mathrm{kcal} /$ day. Using values derived from a database of doubly labelled water (DLW) measures [78], Bouchard [21] identified the "energy gap" in adults to be $>329 \mathrm{kcal} /$ day imbalance for each 5 unit increase in BMI. More recently, Swinburn et al. [79] pooled data from cross-sectional studies with DLW measures of total daily energy expenditure and with data of participant age, sex, height and weight, modeled the "energy gap" (referred to as the energy flux gap) that was theoretically needed to maintain the $\approx 3 \mathrm{~kg}$ weight gain per decade in U.S. adults since the 1970s. The derived models indicated that the energy imbalance was $\approx 400 \mathrm{kcal} /$ day.

There are a number of limitations in these epidemiological studies or those using pooled samples, as numerous assumptions must be made and much information about the cohort is not available.

However, well-controlled, naturalistic longitudinal studies with access to gold-standard methods to measure biology and behavior over a period where weight may be gained at a usual rate are logistically difficult, if not impossible, to undertake. A substitute design is to follow cohorts who have never been overweight, as well as others who have lost weight previously, but exhibit no obvious differences in metabolic phenotype. Weinsier 
et al. [80] identified women who had gained versus maintained weight over a 12-month period, and found that the 'gainers' had a lower AEE, a lower physical activity level, and less muscle strength; with the differences between groups significant from baseline to follow-up. Importantly, these factors are potentially modifiable through changes in patterns of daily living. In contrast, sleeping energy expenditure, exercise economy, and sleeping or 24-h substrate utilization were not significantly different between the two groups. The lower AEE in the gainers explained approximately $77 \%$ of their greater weight gain after 1 year, suggesting a much stronger influence than dietary intake. Schoeller et al. reported similar findings in another follow-up study of previously obese women [81].

The National Weight Control Registry, established in 1993 to examine characteristics of successful weight-loss maintainers, is the largest ongoing study of individuals who have successfully maintained weight loss of at least $13.6 \mathrm{~kg}$ for a minimum of 1 year [82-86]. Collectively, the results have emphasized the importance of healthy lifestyle behaviors to long-term weight maintenance, and avoiding recidivism. Behaviors such as: reduced television watching $(\leq 5 \mathrm{~h} /$ $w k$ ), eating a relatively low-fat diet, eating breakfast almost every day, weighing regularly, and engaging in high levels (about $1 \mathrm{~h} /$ day) of physical activity, were strongly related to preventing weight regain. These finding provide support for the importance of behavior in countering weight gain, especially if this cohort of individuals with a history of overweight and obesity has a genetic predisposition. However, again much of the data is from self-report methods.

Conclusions from the Foresight report were that research into the metabolic aspects of energy expenditure in humans has yielded little to explain weight gain [87]. It was proposed that in controlled experimental conditions in which lean and obese individuals are over- or underfed, there are similar rates of weight gain or loss [88], and therefore physiological differences between people are not the root cause of obesity [5]. However, not all researchers would concur with these conclusions, particularly when diets of different macronutrient content are considered [89].

Galgani and Ravussin [25] reviewed the data from longitudinal studies of weight gain in the Pima Indian population in Arizona, which has a high prevalence of obesity and weight gain is common among young adults. In these studies, four metabolic measures were found to be predictive of weight gain: low REE, low spontaneous physical activity, low sympathetic nervous system activity, and low fat oxidation. Collectively, these four predictors explained approximately $30 \%$ of the variability in weight gain in Pima Indians [25]. Whether all of these factors should be considered independent to behavior may be debated. In any case, in this genetically obesity-predisposed cohort, there remains
$70 \%$ of the weight gain variance unexplained by the biological variables measured. A large proportion of the remainder is very likely behavioral.

The available research data examining the biology and behavior of weight gain is extensive, and we have provided no more than a brief review. There are numerous candidates vying for selection as central players in the etiology of positive energy balance and weight gain. In Table 1 we have provided a commentary of the relevance and significance of a small selection of recent research papers that propose possible determinants of weight gain. It is important to note, that the line between biology and behavior is not always a clear differentiation.

\section{Conclusions}

While body weight regulation involves both biological and behavioral factors, what plays the primary role in enabling a positive energy balance remains unclear. It is very likely that as there are different 'obesities', there are different factors playing the leading role in causing the energy imbalance that leads to weight gain. In this paper we provide evidence to support the argument that biology indiscriminately dictates it is easier to gain than to lose weight, and that variance in the size of the defense is also biologically determined. However, the weight of evidence suggests that behavior is the stronger contributing factor explaining individual differences in weight gain. The extent to which these behaviors are driven by biological (genetic) signaling remains to be determined.

Disclosure No potential conflicts of interest relevant to this article were reported.

\section{References}

Papers of particular interest, published recently, have been highlighted as:

- Of importance

1. International Obesity Task Force. Obesity the Global Epidemic. 2010. http://www.iaso.org/iotf/obesity/obesitytheglobalepidemic/ . Accessed Feb 152012.

2. Swinburn BA, Sacks G, Hall KD, McPherson K, Finegood DT, Moodie ML, et al. The global obesity pandemic: shaped by global drivers and local environments. Lancet. 2011;378(9793):804-14.

3. Giskes K, van Lenthe F, Avendano-Pabon M, Brug J. A systematic review of environmental factors and obesogenic dietary intakes among adults: are we getting closer to understanding obesogenic environments? Obes Rev. 2011;12(5):e95-e106.

4. Gortmaker SL, Swinburn BA, Levy D, Carter R, Mabry PL, Finegood DT, et al. Changing the future of obesity: science, policy, and action. Lancet. 2011;378(9793):838-47. 
5. Vandenbroeck IP, Goossens J, M. C. Foresight Tackling Obesities: Future Choices-Obesity System Atlas., Government Office for Science, UK Government's Foresight Programme http://www.foresight.gov.uk/Obesity/11.pdf

6. Farooqi IS, O'Rahilly S. Genetics of obesity in humans. Endocr Rev. 2006;27(7):710-8.

7. Montague CT, Farooqi IS, Whitehead JP, Soos MA, Rau H, Wareham NJ, et al. Congenital leptin deficiency is associated with severe early-onset obesity in humans. Nature. 1997;387 (6636):903-8.

8. Loos RJ. Genetic determinants of common obesity and their value in prediction. Best Pract Res Clin Endocrinol Metab. 2012;26(2):211-26.

9. Bouchard C, Tremblay A, Despres JP, Nadeau A, Lupien PJ, Theriault $\mathrm{G}$, et al. The response to long-term overfeeding in identical twins. N Engl J Med. 1990;322(21):1477-82.

10. Garland T, Schutz H, Chappell MA, Keeney BK, Meek TH, Copes LE, et al. The biological control of voluntary exercise, spontaneous physical activity and daily energy expenditure in relation to obesity: human and rodent perspectives. J Exp Biol. 2011;214(2):206-29.

11. Harrold JA, Dovey TM, Blundell JE, Halford JCG. CNS regulation of appetite. Neuropharmacology. 2012;63(1):3-17.

12. Heal DJ, Smith SL, Jones RB. Central regulation of food intake and energy expenditure. Neuropharmacology. 2012;63(1):1-2.

13. McAllister EJ, Dhurandhar NV, Keith SW, Aronne LJ, Barger J, Baskin M, et al. Ten putative contributors to the obesity epidemic. Crit Rev Food Sci Nutr. 2009;49(10):868-913.

14. Parker JA, Bloom SR. Hypothalamic neuropeptides and the regulation of appetite. Neuropharmacology. 2012;63(1):18-30.

15. Symonds ME, Pope M, Sharkey D, Budge H. Adipose tissue and fetal programming. Diabetologia. 2012;55(6):1597-606.

16. van Marken Lichtenbelt WD, Schrauwen P. Implications of nonshivering thermogenesis for energy balance regulation in humans. Am J Physiol Regul Integr Comp Physiol. 2011;301(2):R285-96.

17. Colley R, Hills A, King N, Byrne N. Exercise-induced energy expenditure: implications for exercise prescription and obesity. Patient Educ Couns. 2010;79(3):327-32.

18. He K, Hu FB, Colditz GA, Manson JE, Willett WC, Liu S. Changes in intake of fruits and vegetables in relation to risk of obesity and weight gain among middle-aged women. Int J Obes Relat Metab Disord. 2004;28(12):1569-74.

19. Saris WHM, Blair SN, Van Baak MA, Eaton SB, Davies PSW, Di Pietro L, et al. How much physical activity is enough to prevent unhealthy weight gain? outcome of the IASO 1st stock conference and consensus statement. Obes Rev. 2003;4(2):101-14.

20. Sullivan EL, Cameron JL. A rapidly occurring compensatory decrease in physical activity counteracts diet-induced weight loss in female monkeys. Am J Physiol Regul Integr Comp Physiol. 2010;298(4):R1068-74.

21. Bouchard C. The magnitude of the energy imbalance in obesity is generally underestimated. Int J Obes (Lond). 2008;32(6):879-80.

22. Hall KD, Sacks G, Chandramohan D, Chow CC, Wang YC, Gortmaker SL, et al. Quantification of the effect of energy imbalance on bodyweight. Lancet. 2011;378(9793):826-37.

23. Alpert SS. Growth, thermogenesis, and hyperphagia. Am J Clin Nutr. 1990;52(5):784-92.

24. Bray GA. Luxuskonsumption - myth or reality? Obes Res. 1995;3(5):491-5.

25. Galgani J, Ravussin E. Energy metabolism, fuel selection and body weight regulation. Int J Obes (Lond). 2008;32 Suppl 7: S109-19.

26. Del Corral P, Chandler-Laney PC, Casazza K, Gower BA, Hunter GR. Effect of dietary adherence with or without exercise on weight loss: a mechanistic approach to a global problem. J Clin Endocrinol Metab. 2009;94(5):1602-7.
27. Goele K, Bosy-Westphal A, Rumcker B, Lagerpusch M, Muller MJ. Influence of changes in body composition and adaptive thermogenesis on the difference between measured and predicted weight loss in obese women. Obesity Facts. 2009;2(2):105-9.

28. Hall KD. Predicting metabolic adaptation, body weight change, and energy intake in humans. Am J Physiol Endocrinol Metab. 2010;298(3):E449-66.

29. Heymsfield SB, Harp JB, Reitman ML, Beetsch JW, Schoeller DA, Erondu N, et al. Why do obese patients not lose more weight when treated with low-calorie diets? a mechanistic perspective. Am J Clin Nutr. 2007;85(2):346-54.

30. Byrne NM, Wood RE, Schutz Y, Hills AP. Does metabolic compensation explain the majority of less-than-expected weight loss in obese adults during a short-term severe diet and exercise intervention? Int J Obes (Lond). 2012.

31. Bray GA, Flatt JP, Volaufova J, Delany JP, Champagne CM. Corrective responses in human food intake identified from an analysis of 7-d food-intake records. Am J Clin Nutr. 2008;88 (6):1504-10.

32. Suarez R. The biology of energy expenditure. J Exp Biol. 2011;214(2):163.

33. Tremblay A, Royer MM, Chaput JP, Doucet E. Adaptive thermogenesis can make a difference in the ability of obese individuals to lose body weight. Int J Obes (Lond). 2012.

34. Grande F, Anderson JT, Keys A. Changes of basal metabolic rate in Man in semistarvation and refeeding. J Appl Physiol. 1958;12 (2):230-8.

35. James W, Shetty P. Metabolic adaptation and energy requirements in developing countries. Hum Nutr Clin Nutr. 1982;36(5):331-6.

36. Keys A, Brozek J, Henschel A, Mickelson O, Taylor H. The biology of human starvation. St Paul: University of Minnesota Press; 1950.

37. Weinsier RL, Nagy TR, Hunter GR, Darnell BE, Hensrud DD, Weiss HL. Do adaptive changes in metabolic rate favor weight regain in weight-reduced individuals? an examination of the setpoint theory. Am J Clin Nutr. 2000;72(5):1088-94.

38. Capel F, Viguerie N, Vega N, Dejean S, Arner P, Klimcakova E, et al. Contribution of energy restriction and macronutrient composition to changes in adipose tissue gene expression during dietary weight-loss programs in obese women. J Clin Endocrinol Metab. 2008;93(11):4315-22.

39. Franck N, Gummesson A, Jernas M, Glad C, Svensson P-A, Guillot $\mathrm{G}$, et al. Identification of adipocyte genes regulated by caloric intake. J Clin Endocrinol Metab. 2011;96(2):E413-8.

40. Alpert S. A two-reservoir energy model of the human body. Am J Clin Nutr. 1979;32(8):1710-8.

41. Byrne NM, Wood RE, Hills AP. Relationship between body composition and resting metabolic rate becomes stronger during energy restriction in obese adults. Obes Rev. 2011;12 (Supplement s1):71.

42. Sainsbury A, Zhang L. Role of the hypothalamus in the neuroendocrine regulation of body weight and composition during energy deficit. Obes Rev. 2012;13(3):234-57.

43. Douyon L, Schteingart D. Effect of obesity and starvation on thyroid hormone, growth hormone, and cortisol secretion. Endocrinol Metab Clin North Am. 2002;31(1):173-89.

44. Hukshorn C, Menheere P, Westerterp-Plantenga M, Saris W. The effect of pegylated human recombinant leptin (PEG-OB) on neuroendocrine adaptations to semi-starvation in overweight men. Eur J Endocrinol. 2003;148(6):649-55.

45. Naslund E, Andersson I, Degerblad M, Kogner P, Kral JG, Rossner S, et al. Associations of leptin, insulin resistance and thyroid function with long-term weight loss in dieting obese men. J Intern Med. 2000;248(4):299-308.

46. Friedl KE, Moore RJ, Hoyt RW, Marchitelli LJ, Martinez-Lopez LE, Askew EW. Endocrine markers of semistarvation in healthy 
lean men in a multistressor environment. J Appl Physiol. 2000;88 (5): $1820-30$

47. Martins C, Kulseng B, King NA, Holst JJ, Blundell JE. The effects of exercise-induced weight loss on appetite-related peptides and motivation to Eat. J Clin Endocrinol Metab. 2010;95 (4): $1609-16$

48. King JA, Wasse LK, Ewens J, Crystallis K, Emmanuel J, Batterham RL, et al. Differential acylated Ghrelin, peptide YY3-36, appetite, and food intake responses to equivalent energy deficits created by exercise and food restriction. J Clin Endocrinol Metab. 2011;96(4):1114-21.

49. Drapeau V, Blundell J, Therrien F, Lawton C, Richard D, Tremblay A. Appetite sensations as a marker of overall intake. Br J Nutr. 2005;93(2):273-80.

50. Drapeau V, King N, Hetherington M, Doucet E, Blundell J, Tremblay A. Appetite sensations and satiety quotient: predictors of energy intake and weight loss. Appetite. 2007;48(2):159-66.

51. Pasman WJ, Saris WH, Westerterp-Plantenga MS. Predictors of weight maintenance. Obes Res. 1999;7(1):43-50.

52. MacLean PS, Higgins JA, Johnson GC, Fleming-Elder BK, Donahoo WT, Melanson EL, et al. Enhanced metabolic efficiency contributes to weight regain after weight loss in obesity-prone rats. Am J Physiol Regulatory Integrative Comp Physiol. 2004;287(6):R1306-15.

53. Sainsbury A, Rohner-Jeanrenaud F, Cusin I, Zakrzewska K, Halban P, Gaillard R, et al. Chronic central neuropeptide Y infusion in normal rats: status of the hypothalamo-pituitaryadrenal axis, and vagal mediation of hyperinsulinaemia. Diabetologia. 1997;40(11):1269-77.

54. Martin CK, Heilbronn LK, de Jonge L, DeLany JP, Volaufova J, Anton SD, et al. Effect of calorie restriction on resting metabolic rate and spontaneous physical activity. Obesity (Silver Spring). 2007;15(12):2964-73.

55. Martin CK, Das SK, Lindblad L, Racette SB, McCrory MA, Weiss EP, et al. Effect of calorie restriction on the free-living physical activity levels of nonobese humans: results of three randomized trials. J Appl Physiol. 2011;110(4):956-63.

56. Rosenbaum M, Vandenborne K, Goldsmith R, Simoneau JA, Heymsfield S, Joanisse DR, et al. Effects of experimental weight perturbation on skeletal muscle work efficiency in human subjects. Am J Physiol Regul Integr Comp Physiol. 2003;285(1): R183-92.

57. Stubbs RJ, Hughes DA, Johnstone AM, Whybrow S, Horgan GW, King N, et al. Rate and extent of compensatory changes in energy intake and expenditure in response to altered exercise and diet composition in humans. Am J Physiol Regulatory Integrative Comp Physiol. 2004;286(2):R350-8.

58. Vaanholt LM, Magee V, Speakman JR. Factors predicting individual variability in diet-induced weight loss in MF1 mice. Obesity (Silver Spring). 2012;20(2):285-94.

59. Clapham JC. Central control of thermogenesis. Neuropharmacology. 2012;63(1):111-23.

60. Bolster DR, Crozier SJ, Kimball SR, Jefferson LS. AMPactivated protein kinase suppresses protein synthesis in rat skeletal muscle through down-regulated mammalian target of rapamycin (mTOR) signaling. J Biol Chem. 2002;277(27):23977-80.

61. Carbone JW, McClung JP, Pasiakos SM. Skeletal muscle responses to negative energy balance: effects of dietary protein. Adv Nutr. 2012;3(2):119-26. doi:10.3945/an.111.001792.

62. Wells JCK. An evolutionary perspective on the trans-generational basis of obesity. Ann Hum Biol. 2011;38(4):400-9.

63. Deriaz O, Tremblay A, Bouchard C. Non linear weight gain with long term overfeeding in man. Obes Res. 1993;1 (3):179-85.

64. Bouchard C, Tremblay A. Genetic influences on the response of body fat and fat distribution to positive and negative energy balances in human identical twins. J Nutr. 1997;127(5 Suppl):943S-7S.

65. Deriaz O, Fournier G, Tremblay A, Despres JP, Bouchard C. Lean-body-mass composition and resting energy expenditure before and after long-term overfeeding. Am J Clin Nutr. 1992;56 (5):840-7.

66. Tremblay A, Despres JP, Theriault G, Fournier G, Bouchard C. Overfeeding and energy expenditure in humans. Am J Clin Nutr. 1992;56(5):857-62.

67. Oken E, Kleinman KP, Belfort MB, Hammitt JK, Gillman MW. Associations of gestational weight gain with short- and longerterm maternal and child health outcomes. Am J Epidemiol. 2009;170(2):173-80.

68. Hales CN, Barker DJ. The thrifty phenotype hypothesis. Br Med Bull. 2001;60:5-20.

69. Yajnik CS. Obesity epidemic in India: intrauterine origins? Proc Nutr Soc. 2004;63(03):387-96.

70. Rattanatray L, MacLaughlin SM, Kleemann DO, Walker SK, Muhlhausler BS, McMillen IC. Impact of maternal periconceptional overnutrition on Fat mass and expression of adipogenic and lipogenic genes in visceral and subcutaneous Fat depots in the postnatal lamb. Endocrinology. 2010;151(11):5195-205.

71. Micke GC, Sullivan TM, McMillen IC, Gentili S, Perry VEA. Heifer nutrient intake during early- and mid-gestation programs adult offspring adiposity and mRNA expression of growth-related genes in adipose depots. Reproduction. 2011;141(5):697-706.

72. Zhang S, Rattanatray L, McMillen IC, Suter CM, Morrison JL. Periconceptional nutrition and the early programming of a life of obesity or adversity. Prog Biophys Mol Biol. 2011;106(1):30714.

73. Ng SF, Lin RC, Laybutt DR, Barres R, Owens JA, Morris MJ. Chronic high-fat diet in fathers programs beta-cell dysfunction in female rat offspring. Nature. 2010;467(7318):963-6.

74. Samocha-Bonet D, Campbell LV, Mori TA, Croft KD, Greenfield JR, Turner N, et al. Overfeeding reduces insulin sensitivity and increases oxidative stress, without altering markers of mitochondrial content and function in humans. PLoS One. 2012;7(5): e36320.

75. Hill JO, Wyatt HR, Reed GW, Peters JC. Obesity and the environment: where do we go from here? Science. 2003;299 (5608):853-5. doi:10.1126/science.1079857.

76. Butte NF, Ellis KJ. Comment on "obesity and the environment: where do we go from here?". Science. 2003;301(5633):598.

77. Wang YC, Gortmaker SL, Sobol AM, Kuntz KM. Estimating the energy gap among US children: a counterfactual approach. Pediatrics. 2006;118(6):e1721-33.

78. Institute of Medicine. Panel on Macronutrients SoURLoNIaUoDRI, Intakes SCotSEoDR. Dietary Reference Intakes for Energy, Carbohydrate, Fiber, Fat, Fatty Acids, Cholesterol, Protein, and Amino Acids (Macronutrients): The National Academies Press2005. Report No.: 9780309085250.

79. Swinburn BA, Sacks G, Lo SK, Westerterp KR, Rush EC, Rosenbaum M, et al. Estimating the changes in energy flux that characterize the rise in obesity prevalence. Am J Clin Nutr. 2009;89(6):1723-8.

80. Weinsier RL, Hunter GR, Desmond RA, Byrne NM, Zuckerman PA, Darnell BE. Free-living activity energy expenditure in women successful and unsuccessful at maintaining a normal body weight. Am J Clin Nutr. 2002;75(3):499-504.

81. Schoeller DA, Shay K, Kushner RF. How much physical activity is needed to minimize weight gain in previously obese women? Am J Clin Nutr. 1997;66(3):551-6.

82. Catenacci VA, Grunwald GK, Ingebrigtsen JP, Jakicic JM, McDermott MD, Phelan S, et al. Physical activity patterns using accelerometry in the national weight control registry. Obesity (Silver Spring). 2011;19(6):1163-70. 
83. Catenacci VA, Ogden LG, Stuht J, Phelan S, Wing RR, Hill JO, et al. Physical activity patterns in the national weight control registry. Obesity (Silver Spring). 2008;16(1):153-61.

84. Raynor DA, Phelan S, Hill JO, Wing RR. Television viewing and long-term weight maintenance: results from the national weight control registry. Obesity (Silver Spring). 2006;14(10):1816-24.

85. Wyatt HR, Grunwald GK, Mosca CL, Klem ML, Wing RR, Hill JO. Long-term weight loss and breakfast in subjects in the national weight control registry. Obes Res. 2002;10(2):78-82.

86. Wyatt HR, Grunwald GK, Seagle HM, Klem ML, McGuire MT, Wing RR, et al. Resting energy expenditure in reduced-obese subjects in the national weight control registry. Am J Clin Nutr. 1999;69(6):1189-93.

87. Prentice A. Are defects in energy expenditure involved in the causation of obesity? Obes Rev. 2007;8 Suppl 1:89-91.

88. Lang T, Rayner G. Overcoming policy cacophony on obesity: an ecological public health framework for policymakers. Obes Rev. 2007;8 Suppl 1:165-81.

89. Stock MJ. Gluttony and thermogenesis revisited. Int J Obes Relat Metab Disord. 1999;23(11):1105-17.

90. • Bostrom P, Wu J, Jedrychowski MP, Korde A, Ye L, Lo JC, et al. A PGC1-[agr]-dependent myokine that drives brown-fat-like development of white fat and thermogenesis. Nature. 2012;481 (7382):463-8. The importance of the study were presented in Table 1.

91. • Elks CE, Loos RJ, Hardy R, Wills AK, Wong A, Wareham NJ, et al. Adult obesity susceptibility variants are associated with greater childhood weight gain and a faster tempo of growth: the 1946 British birth cohort study. Am J Clin Nutr. 2012;95(5):1150-6. The importance of the study were presented in Table 1.

92. • Faghihnia N, Siri-Tarino PW, Krauss RM, Brooks GA. Energy substrate partitioning and efficiency in individuals with atherogenic lipoprotein phenotype. Obesity (Silver Spring). 2011;19 (7):1360-5. The importance of the study were presented in Table 1.
93. - Tomiyama AJ, Schamarek I, Lustig RH, Kirschbaum C, Puterman E, Havel PJ, et al. Leptin concentrations in response to acute stress predict subsequent intake of comfort foods. Physiol Behav. 2012;107(1):34-9. The importance of the study were presented in Table 1.

94. - Vijgen GHEJ, Bouvy ND, Teule GJJ, Brans B, Hoeks J, Schrauwen $\mathrm{P}$, et al. Increase in brown adipose tissue activity after weight loss in morbidly obese subjects. J Clin Endocrinol Metab. 2012;97(7):E1229-33. doi:10.1210/jc.2012-1289. The importance of the study were presented in Table 1.

95. - DeLany JP, Kelley DE, Hames KC, Jakicic JM, Goodpaster BH. High energy expenditure masks low physical activity in obesity. Int J Obes. 2012. The importance of the study were presented in Table 1.

96. - St-Onge M-P, Roberts AL, Chen J, Kelleman M, O'Keeffe M, RoyChoudhury A, et al. Short sleep duration increases energy intakes but does not change energy expenditure in normal-weight individuals. Am J Clin Nutr. 2011;94(2):410-6. The importance of the study were presented in Table 1.

97. • Britton KA, Lee IM, Wang L, Gaziano JM, Manson JE, Buring $\mathrm{JE}$, et al. Physical activity and the risk of becoming overweight or obese in middle-aged and older women. Obesity (Silver Spring). 2012;20(5):1096-103. The importance of the study were presented in Table 1.

98. - Gayda M, Juneau M, Nigam A. Comment on the paper by Gibala, little, Macdonald and Hawley entitled physiological adaptations to low-volume, high-intensity interval training in health and disease. J Physiol. 2012;590(14):3389. The importance of the study were presented in Table 1.

99. • Gibala MJ, Little JP, MacDonald MJ, Hawley JA. Physiological adaptations to low-volume, high-intensity interval training in health and disease. J Physiol. 2012;590(5):1077-84. The importance of the study were presented in Table 1.

100. • Caprio S. Calories from soft drinks - do they matter? N Engl J Med. 2012;367(15):1462-3. The importance of the study were presented in Table 1. 